Environmental Health Perspectives is pleased to present this abstract on behalf of the International Society for Environmental Epidemiology (ISEE). This abstract was presented at an ISEE annual meeting and has not been peer reviewed.

\title{
Environmental Contamination from E-Waste Activities: A Systematic Review
}

Karel Gédéon Houessionon, Sylvia Akpene Takyi, Julius Fobil, Marius Kedote, Benjamin Fayomi, Edgard-Marius Ouendo, Catherine Bouland, and Nil Basu

\section{Abstract}

Introduction : The recycling of electronic waste (e-waste) contaminates ecosystems and people with a range of pollutants though to our knowledge the matter has yet to be reviewed through a systematic analysis. Methods : A systematic review process was adopted from the Office of Health Assessment and Translation from the U.S. National Toxicology Program.A full literature search on MEDLINE (PubMed) and Web of science was conducted using a priori key words and MeSH terms. The studies selected in this work are those dealing with heavy metals $(\mathrm{Cd}, \mathrm{Hg}, \mathrm{As}, \mathrm{Pb}$ and $\mathrm{Cr}$ ) in two media (soil and water). In total, 59 scientific papers that met the predefined criteria were identified and included in the review. Among others, the information was collected on the design, location of the study, type of heavy metal, and measurement. Until now a narrative synthesis has been conducted on all included studies with future plans to perform an analytical comparison.Results : In general, the literature provides information on the high contamination of soils, agricultural soils, surface water, river, well water, and drinking water by heavy metals. This contamination ranges from recycling sites to residential areas. More than $70 \%$ of the studies were conducted in Asia. Conversely, in the African region, only few, (\&lt;10\%) studies have examined the problem of environmental contamination by heavy metals from e-waste, although several studies show that the problem is growing.Conclusion : Several studies have addressed the issue, but it is imperative to take a holistic approach of the growing e-waste issue.Key words : e-waste, heavy metals, soil, water, environment

\section{SUBSCRIBE}

to Receive Our Monthly TABLE OF CONTENTS

\section{ehp}
Contact Us $\quad$ Email Alert

$$
\mathrm{f}
$$

Support and Resources

Submit Manuscript

Author Hub

EHP in PubMed Central

About Article Metrics

Get Adobe Reader

\section{About EHP}

Copyright and

Permissions

Section 508 Accessibility

Announcements

EHP in the Media

Editorial Boards 